\title{
Knowledge Management and Academic Libraries
}

\section{Charles T. Townley}

\begin{abstract}
The emerging field of knowledge management offers academic libraries the opportunity to improve effectiveness, both for themselves and their parent institutions. This article summarizes knowledge management theory. Current applications in academic libraries and higher education are described. Similarities and differences between knowledge management and academic library practices are discussed. Issues needing resolution are presented.
\end{abstract}

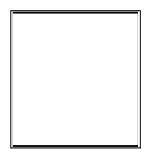

or the past twenty years, academic libraries have generated increasing amounts of information about their operations. Yet, like higher education and industry, libraries rarely use this operational information to create or apply organizational knowledge. Instead, they excuse themselves by saying they are so committed to providing services that there is no time to use this growing body of information to increase organizational effectiveness. In fact, libraries do not consider organizational knowledge as a resource in its own right as they do personnel, collections, or facilities. Librarians do not manage knowledge about their organizations as they manage their other resources. They do not structure their organizations to use organizational knowledge. They do not apply organizational knowledge to improve services or the transmission of scholarly information. For example, libraries, retail stores, and Web sites all generate exact records of use as a by-product of their automated systems; but unlike Amazon.com, few librarians consciously create and then use knowl- edge from that information to improve organizational effectiveness.

Nor do libraries lead their institutions in managing their knowledge. Universities also create vast arrays of information about their operations, yet frequently do not organize or interpret them. Few organizational resources are dedicated to the creation and application of knowledge to organizational problems. Any information apparatus is crude and ineffective by library standards.

The emerging field of knowledge management offers academic libraries the opportunity to create knowledge to improve organizational effectiveness, for both themselves and their institutions. This article is intended to summarize the dynamic field of knowledge management and to describe how it can be used to make academic libraries more effective both inside the library and throughout the institution.

\section{What Is Knowledge Management?}

Colleges, universities, and their libraries are social organizations where workers transform resources for use by consum-

Charles T. Townley is a Professor in the New Mexico State University Library; e-mail: ctownley@lib.nmsu.edu. 
ers through the functions of teaching, research, and service. Also created is a growing amount of transactional information in databases, knowledge embedded in processes and documentation as well as explicit and implicit knowledge in the heads of the workers. As the pace of change increases and people change jobs more frequently, information and knowledge that used to be concentrated in one person or process increasingly is being held by multifunctional teams with limited life spans, operating with rapidly changing systems and environments. Change is the order of the day. Knowledge loss becomes epidemic. Increases in organizational information and change have created a great need to manage knowledge to ensure effectiveness. And in higher education, librarians can play a key role in the knowledge management process. $^{1}$

\section{Knowledge management may be defined as the set of processes that create and share knowledge across an organization to optimize the use of judgment in the attainment of mission and goals.}

What, then, is knowledge management? Knowledge management may be defined as the set of processes that create and share knowledge across an organization to optimize the use of judgment in the attainment of mission and goals. It is an emerging discipline developing on the interstices of organizational psychology, library and information science, economics, and computer science. It involves capturing an organization's goal-related knowledge as well as knowledge of its products, customers, competition, and processes, and then sharing that knowledge with the appropriate people throughout the organization. Further, knowledge management seeks to support communities of practice in creating and using knowledge. Finally, it accepts the notion that knowledge transmission is primarily a human activity. Thus, knowledge management is the art of creating value from an organization's knowledge assets. $^{2}$

Knowledge management has emerged over the past ten years as organizations have striven to increase their effectiveness. Organizations with large knowledge assets have led the effort, including businesses such as IBM, Dow Chemical, and Microsoft and consulting groups such as McKinsey and Arthur Anderson. ${ }^{3}$ As Lew Platt, CEO of Hewlett-Packard said, " If Hewlett-Packard knew what Hewlett-Packard knows, we would be three times more profitable." In the United States, expenditures on knowledge management efforts are expected to reach $\$ 200$ billion in 2000. Knowledge management also is becoming known in public organizations. The first conference on knowledge management in the public sector was held in the spring of 2000 and drew more than a thousand participants, including a small group of academic librarians and faculty. Higher education institutions are beginning to adopt the idea of managing their organizational knowledge assets. ${ }^{4}$

Independently, librarians have developed and applied many knowledge management principles in the provision of academic library services. Reference, cataloging, and other library services are designed to encourage the use of scholarly information and thus increase the amount of academic knowledge used in higher education. Questions in a reference interview and the points of access in a catalog both are intended to reinforce the ways that scholars work to create new academic knowledge. However, libraries have done little to use organizational information to create knowledge that can be used to improve the functionality of library and higher education processes. In many ways, knowledge management incorporates principles that academic librarians have developed and used with scholarly information for many years. It then applies these principles and others to organizational information in ways that create new knowledge to improve organizational effectiveness. ${ }^{5}$ 
Knowledge management emphasizes the human side of knowledge. Knowledge is created in the human brain, and only the right organizational climate can persuade people to share it. Knowledge management is most effective in learning communities with shared vision and practice, line-of-sight relationships, and a sense of community characterized by empathy and trust. Knowledge is treated as a product in its own right. ${ }^{6}$ Much emphasis is placed on achieving selectivity and quality to avoid drowning in the growing seas of organizational data. Traditional and new technologies are applied selectively to strategically important projects in order to achieve organizational objectives. Speed also is important given the need for increased responsiveness and shorter cycle times. Training and support for the adoption of new knowledge and behaviors are perhaps the most important and costly part of any knowledge management application. In large organizations, knowledge management tends to be diverse, discrete, and decentralized. ${ }^{7}$

In Knowledge in Organizations, Lawrence Prusak outlines six environmental issues that are forcing organizations to focus on knowledge. ${ }^{8}$ First, an accelerating world means rapid knowledge decay and the need to create new knowledge more quickly. Knowledge must be managed consciously if workers are to learn fast enough for an organization to remain competitive. Second, smart products, such as selective dissemination of information services, offer knowledge as part of the product. Such knowledge must be current if it is to contribute to the product's value. Third, globalization is creating distributed systems of production. And as more teaching and research take place away from the "main" campus and as libraries outsource more scholarly information and services, more effort must be made to ensure needed access to, and sharing of, knowledge. Fourth, turnover is increasing throughout academia. Knowledge that used to be embedded in one person for a career now leaves as individuals change jobs with greater fre- quency. The coming retirement of large numbers of academics who began careers in the 1960s will create a knowledge deficit situation in academia similar to the corporate downsizing that took place in the 1990s. Fifth, virtual operations require more embedded knowledge to work effectively. A prospective student trying to enroll at 10:00 p.m. is more likely to enroll elsewhere than call back in the morning to ask a number of questions the system cannot answer. Finally, knowledge begets knowledge. As systems become more knowledgeable and interactive, new opportunities to use new knowledge proactively are generated. In sum, knowledge is a key asset of any organization, one that now can be added to the classic assets of facilities, labor, and capital. Although higher education has long held scholarship as an asset, it now also must recognize the value of organizational knowledge applied to organizational processes and services.

Given these parameters and needs, it is clear that knowledge management has a significant future in academic libraries and the academic institutions they serve. It is a growing management technique for organizations. It is beginning to enter publicsector and higher education organizations. Through knowledge management, libraries have an opportunity to collaborate with other units to increase both their effectiveness and that of higher education.

\section{Knowledge Management in Academic Library Operations}

Knowledge management is being used to improve library operations. Special libraries have taken the lead, but some applications now are taking place in other libraries. This section addresses how organizational knowledge can be created and used in internal academic library operations. The discussion of these factors can be expanded for use throughout institutions of higher education.

From a theoretical point of view, knowing can be considered as a pyramid. All knowing begins at the bottom of the pyramid with data and unfiltered facts. When 
context is added, in the case of libraries through cataloging or metadata, data become information. When inference is added, often through public services such as reference, information becomes intelligence. Intelligence combined with certitude becomes knowledge. And at the top, knowledge combined with synthesis becomes wisdom. Libraries have excelled at creating scholarly information and intelligence from data, but they have tended not to create knowledge from intelligence. Moreover, they have not been as successful in generating organizational knowledge to achieve library goals. Knowledge management is one way to develop and apply the organizational knowledge needed to improve library operations and, ultimately, library effectiveness. It also enables libraries to generate organizational knowledge for higher education institutions. ${ }^{9}$

Organizational knowledge can be divided into two groups, depending on its centrality to the organization and its acceptability to workers. Core knowledge is composed of structures that explain broad propositions that are widely held in the organization. Peripheral knowledge supports core knowledge by addressing subcomponents and does not require widespread understanding or consensus. In libraries, beliefs of intellectual freedom are widely held. On the other hand, knowledge of authority files is far more likely to be supported in a cataloging department than in a reference department. Over time, organizational knowledge becomes more complex and interrelated. Although this may improve the shortterm quality of scholarly information provided on any specific operation, it also makes change more difficult for library organizations. And this can have a negative long-term organizational outcome in a time of rapid environmental change. ${ }^{10}$

Frequently, the key to change is the effective use of informal networks in the organization. David Krackhardt and Jeffrey R. Hanson have identified three kinds of informal networks that can be used to effect change. The advice network identifies the leading players on whom others depend. The trust network identifies the relationships used for political maneuvering and crisis support. And the communication network reveals patterns of communication throughout the organization. Effective library managers will develop skills in using each kind of network to collect and transfer organizational knowledge. ${ }^{11}$

\section{A Typology of Organizational Knowledge}

Rob Cross and Lloyd Baird have identified five kinds of knowledge in organizations. ${ }^{12}$ The most important is the knowledge embedded in the minds of workers. This tacit and explicit knowledge is gained through everyday experience on the job. It is shared most commonly in social interactions with other workers. This knowledge can be withheld on a whim, and it can leave the organization with the worker. We all can recall times when the absence of an individual has arrested an organizational initiative in its tracks.

Second, organizational knowledge is explicit and tacit knowledge shared in work groups. As with individuals, this knowledge is subject to loss with the elimination or restructuring of a work group. At one point during corporate downsizing, for example, one of the Big Three automakers had eliminated so many employees that management found it lacked the knowledge required to design a new car and bring it into production. People had to be brought back onto the payroll, now as expensive consultants, to get new designs out the door.

Third, organizations can create knowledge repositories composed of explicit knowledge that has been documented and organized for access. Often these are called data warehouses or data malls. Frequently, they resemble libraries or archives in some respects. The knowledge is collected and organized in some symbolic form, such as a catalog or a bibliography. Authorized users may access the knowledge. To continue the saga of the 
automaker, a "big book" of auto design was created with all the knowledge considered critical for designing and producing a new-model vehicle. By documenting this knowledge, the automaker is less susceptible to loss of knowledge through downsizing or turnover. However, knowledge repositories also have limitations. They can include only a fraction of the most important data to an organization. Unless updated constantly, repositories quickly go out of date. In addition, they always will be consulted second, after colleagues and coworkers.

Sometimes the fact that organizational processes themselves contain a great deal of embedded knowledge is overlooked. This is the fourth type of organizational knowledge. The way that work is organized and carried out incorporates a great deal of knowledge. For example, current cataloging practice is based on the knowledge that OCLC can provide acceptable cataloging information for more than 90 percent of the items that a typical academic library adds to its collection. This one piece of knowledge has been embedded in the radical redesign of cataloging operations in recent years.

Finally, knowledge is embedded in products and services. Academic libraries focus on delivering scholarly information and support services. In the past, this involved printed, and sometimes recorded, media almost exclusively. Like IBM ignoring the emerging personal computer market in the 1980s, libraries risk losing their role as the primary academic information provider if they do not address the knowledge that most users are requesting electronic formats in the provision of resources and services.

The collection, processing, and dissemination of organizational knowledge will seem familiar to most librarians. Frequently, it mimics the process that academic libraries use to process scholarly knowledge. Good selection is paramount. In the case of organizational knowledge, librarians need to select and use the knowledge that is most critical to achieving library goals. For example, if a library is committed to increasing the effectiveness of its internet portal and catalog, it would need to create knowledge from usage data, including user behavior such as databases accessed, failure rates, persistence rates, and so forth. The library then can benchmark against other libraries to identify areas of comparative strength and weakness. In addition, it can collect best practices to share with staff and users to generate more effective (desired) use. On the other hand, some knowledge, such as hour or day of use or major, might be considered less important for reaching goals and not be included in the knowledge system. ${ }^{13}$

Organization of knowledge also is critical for improving library operations. Knowledge must be structured in ways that are intuitive for the intended community of practice. Knowledge that is intuitive for catalogers may not be immediately intuitive for an archivist or reference librarian, and vice versa. Implicit knowledge must be divided into broad groups of similar knowledge with excellent transferal capability. Explicit knowledge must use structured subject descriptors to maintain order and accessibility. Descriptors are dynamic and must be updated constantly to represent changes in the field. Librarians excel at this type of work. Organizing library operational knowledge needs only the organizational will and resources to occur. ${ }^{14}$

Librarians are learning to be proactive in their delivery of scholarly knowledge and will need to use many of the same techniques to share operational knowledge within the library. Commitment, training, and support are key factors in the transfer of knowledge. If library personnel are not committed to achieving library goals, or if they are not well trained in the use of organizational knowledge, it is likely that efforts to manage knowledge will fail. Both are necessary prerequisites. Should a selector, for example, fail to be familiar with or use available knowledge about collection use or implicit knowledge about faculty interests and goals in making access and selection de- 
cisions, it is unlikely that the library will have the information that meets scholars' needs. For this purpose, the person responsible for collection development needs to ensure that appropriate knowledge and the opportunities to learn it are available to each selector. Continuing support also is important. Librarians need to be encouraged and rewarded constantly for applying useful knowledge to achieve organizational goals. The intent of this area is to expand and support the use of knowledge-based judgments to achieve library goals.

Finally, as with all management processes, knowledge management efforts need to be evaluated and updated. Knowledge that improves effectiveness needs to be identified and supported. Other knowledge needs to be revised or eliminated. In the dynamic world of academic libraries, no library will succeed for very long when it is not managing its most valuable resource, its knowledge, as effectively as possible.

\section{Knowledge Management Processes}

Drawing on a survey of thirty-one knowledge management projects, Thomas $\mathrm{H}$. Davenport, David W. De Long, and Michael C. Beers identified four types, each of which focuses on a broad objective: (1) to create knowledge repositories; (2) to improve knowledge access; (3) to enhance the knowledge environment; and (4) to manage knowledge as an asset. ${ }^{15}$ The following subsections describe how each of these types of projects can be applied in academic libraries.

\section{Create Knowledge Repositories}

Librarians are familiar with knowledge repositories. In terms of library operational information, most integrated library systems contain a component intended to provide useful information about library operation and user activity. This kind of information can be used to create explicit organizational knowledge, to inform services, to guide operations, and to measure goal attainment. Data about new monographs, for example, are created routinely when these items are added to the collection. These data could be combined with circulation data and online reviews to create notices for distribution to prospective readers. Or, usage data from an electronic reserve service could be aggregated and sent to the instructor in time to modify class activities to take advantage of what has been used. In each of these cases, data that are collected routinely as part of the operation of the integrated library system can be used to create and share knowledge that contributes to the improvement of teaching and research. By creating knowledge from existing data, libraries add value to integrated library systems.

External knowledge repositories also can be used to achieve organizational objectives. Several years ago, faculty in the College of Engineering at New Mexico State University adopted the goal of quality, rather than quantity, in scholarly publishing. Working with the library, faculty used information from the Institute for Scientific Information and other resources as tools for determining where to publish their scholarly research. The result has been that the School of Electrical Engineering ranked in the top ten for publication impact this year as measured by the Institute of Scientific Information. ${ }^{16}$

\section{Improve Knowledge Access}

A second type of knowledge management project is one that improves access to and transfer of organizational knowledge. This often takes place by creating expert networks where individuals with desired expertise are organized formally into a network and put into contact with others, creating a community of interest. An example might be a network of subject specialists, perhaps from several institutions, who come together to share experiences and learn from each other. Another method is to create yellow pages, classifying individuals by different areas of expertise into a logical whole. Internal cross-training and exchange with other organizations also are used. 
The National Institute of Standards and Technology (NIST) has created a virtual library to complement and reinforce existing library services and to encourage increased knowledge transfer. The virtual library emphasizes services that are proactive, such as selective dissemination of information and document delivery. In addition, research consultants combine tacit knowledge drawn from working directly on research teams with knowledge of the virtual library to identify and transfer useful research information directly to users. The result is more highly focused provision of appropriate scholarly information in formats and at times convenient to the users. ${ }^{17}$

Often technological innovations can enhance the knowledge process. Lotus Notes and Intranets are popular in private organizations; electronic mail and hosted listservs are popular in public organizations. British Petroleum has had great success in using videoconferencing to speed up repairs by eliminating repair crew travel. ${ }^{18}$ The library at New Mexico State University approached e-mail as a strategic knowledge resource in the early 1990s. The result has been the creation and application of organizational knowledge to optimize the effectiveness of e-mail in organizational activities. ${ }^{19}$

\section{Enhance the Knowledge Environment}

Enhancing the knowledge environment is the third type of knowledge management process. It focuses on creating an environment that encourages the creation and transfer of knowledge. If the tacit knowledge about users held by a reference librarian could be shared with systems personnel, for example, a more effective library home page would result. To create an environment supporting this kind of knowledge, management must generate meaningful contacts among the staff, provide resources and incentives, and praise progress. The NIST virtual library also can serve as a useful example for enhancing knowledge environments. In addition to providing an integrated library system and connectivity to other electronic resources, it supports the Electronic Information and Publications Programs as the access portal for the NIST publication database and for delivering electronic documents for the entire organization. Both the library and the electronic publication program benefit from this cooperative environment. The library gains additional information resources of high internal value, and the electronic program does not have to support the distribution of the information.

\section{Manage Knowledge as an Asset}

Managing knowledge as an asset is the last type of knowledge management project and perhaps the least familiar to librarians. Although some companies audit their intellectual resources internally each year, libraries tend to simply list their physical holdings and easily quantifiable activities, assuming that each item or activity measured is equally valuable and goal related. Some firms manage their intellectual capital to achieve maximum return, something most librarians have not considered. What would happen if librarians began to manage the library's assets explicitly to achieve maximum return? How would libraries value the operations knowledge in the heads of library workers? How should libraries value the knowledge embedded in their processes and products? How should they value the growing amount of information to which they have electronic access? It is no longer enough for library leaders to make intuitive decisions. To achieve quality, commitment, and acceptability, these decisions must be based on organizational knowledge and made collaboratively. The cross-organizational committee systems developed by the Kao and Sharp Corporations in Japan provide a way to create and manage organizational knowledge. In both companies, opportunities for innovation are presented on a regular basis, reallocation of resources is argued, and decisions are made to support the promising initiatives on a temporary, but corporation-wide, basis. After evaluation, the best initiatives are implemented. ${ }^{20}$ 
The Association of Research Libraries (ARL) and the Big Twelve Plus Research Library Consortium both have projects intended to manage scholarly information as an asset. In these collaboratives, libraries are directly cosponsoring the publication of journals in high-cost fields of scholarship. In so doing, they are working with authors and publishers to achieve reduced costs and improve the quality of scholarly information. In time, operational information will be used to create knowledge on the effectiveness of these efforts to manage scholarly information as an asset.

\section{Librarians can use knowledge management as a way to expand the library's role to areas such as administration or support services, where libraries have had little impact in the past.}

In summary, knowledge management is being introduced into academic libraries. It is most likely to be addressed by libraries that have strategic goals, involve their users, work as learning organizations, recognize technology as a functional tool, and are organized in crossfunctional teams. Internally, knowledge management is one more tool for designing effective library service. In addition, it can lead to a larger role for libraries in the broader academic community.

\section{Larger Role for Academic Libraries}

In the corporate community, special libraries have been involved in knowledge management from its beginnings. Libraries, along with computer centers, research units, personnel, and business offices, provide the leadership for corporate efforts. Librarians, such as Trish Foy, Laurence Prusak, and Paul Vassallo, have assumed leadership roles.

In the same way, academic librarians can benefit their institutions, their libraries, and themselves by undertaking a campuswide role in managing organizational knowledge. They can use knowledge management as a way to expand the library's role to areas such as administration or support services, where libraries have had little impact in the past. Moreover, they can develop cross-functional teams with units such as computing, instructional technology, institutional planning, and personnel to create collaborative organizations that have major institutional missions and responsibilities.

Higher education is in the midst of major change as accountability, technology, faculty aging, distance education, and many other pressures come to bear. Knowledge management offers an opportunity to manage some of these issues and achieve institutional goals by using organizational knowledge. Libraries can bring specific skills in the selection and organization of knowledge, training, and user support to cross-functional teams. By doing so, they can create increased interest and support for their other missions. In the apocryphal words of the old sage, it is a risk that most libraries cannot afford not to take. ${ }^{21}$

Many universities have developed data warehouses or, more often, data malls made up of disparate collections of unrelated operational data-culled from elsewhere and compiled together in one massive database with common searchware. Many data warehouses focus only on those data elements required for reporting to state and national agencies and tend to ignore anything else, including data that could lead to knowledge about achieving organizational goals. Usually, the searchware is so complex that only a few people know how to use it. There is no training or support. In short, most warehouses and malls are not very useful. Academic libraries could add a great deal of value to data warehouses by undertaking needs assessments to find out what kinds and forms of knowledge would be helpful to administrative and academic personnel in achieving organizational goals. Librarians could structure the database and search algorithms to create useful information and intelligence in appropriate areas. In addition, they could distribute that information and intelligence in a form the user finds meaningful for achieving objectives. Finally, 
they could train and support use of the data warehouse. These are all skills for which librarians are recognized in the academic community. Supporting data warehouses would only expand traditional library activities to a new set of information. It also would bring the library in much closer contact with operational units such as the computer center, legislative affairs, and institutional research, as well as senior academic administrators, creating two new groups of library users on campus-administration and support services. The costs of a project for a comprehensive data warehouse would be significant. But broken into goal-related components related to university goals, the costs can be controlled and the benefits demonstrated.

The Oak Ridge National Laboratory Library, in collaboration with systems, records, and information units, has developed an organization-wide effort to improve access to strategic knowledge, the second type of knowledge management. ${ }^{22}$ It is built upon six goals: (1) universal access (users have easy access); (2) collaborative environment (with users and tools); (3) transparency (fluid movement of knowledge and work); (4) integration (use of flexible interfaces to meet unique needs); (5) intelligent tools for leveraging knowledge; and (6) computing as a tool (modeling and simulation are integral to the service). Currently, the library is developing a Virtual Proposal Support Center as a pilot project to demonstrate how these goals can be attained. This center will improve access to knowledge about grants and proposals of interest to Oak Ridge. It will pull together several databases into a single searching algorithm, maintain a list of experts available to support a proposal, and provide access to other proposals and lessons learned. Moreover, it will include similar knowledge from collaborating institutions. Finally, it is intended to provide one-stop shopping for scientists putting together increasingly complex and multidisciplinary proposals in a distributed environment. The center relates to Oak Ridge Laboratory goals to increase the amount and diversity of science being conducted and to build collaborative relationships.

The Oak Ridge Library believes that the successful implementation of any knowledge management project involves six requirements. First, the laboratory management must foster knowledge sharing and collaboration within the organization, something new for an organization that used to pride itself on individuals doing classified work. Second, leadership support must be present at all levels of the organization. Third, strong collaboration must exist between computing and library organizations. Fourth, librarians must develop new skills and new ways of working. And time, persistence, experimentation, and flexibility are required of all participants in the pilot project. Finally, all administrators must demonstrate proactive leadership. ${ }^{23}$

The University of New Mexico Health Sciences Center is establishing an environment more conducive for knowledge creation, transfer, and use. It has established a campuswide Advisory Council for Knowledge Management and Information Technology. With representation from all major providers and users, this council is charged to envision the future for knowledge and technology within the center. It is to identify knowledge needs in traditional areas such as curriculum, research, and patient care, as well as areas new to most libraries such as administrative services, public access, and training. The council will meet monthly and advise the directors of the library, computing, and instructional technology units. The intent is to develop integrated responses to knowledge needs that will result in the attainment of university goals. As one of four major committees at the center, its broad charge will give the council the opportunity to support knowledge development throughout the organization. Its diverse membership will ensure organizational support. The library, computing, and instructional technology units will provide the staff to test and implement council initiatives. ${ }^{24}$ 
Finally, the NIST Office of Information Services now is responsible for the management of knowledge throughout the institute. In addition to organizing and accessing both scholarly and organizational information and providing electronic support, it is involved in the creation of knowledge, including the administration of editorial boards and publications. This combination of libraries, information technology, and publishing has resulted in a knowledge unit able to manage the knowledge assets of the organization very effectively.

Although these are only beginnings, they give an indication of the ability of knowledge management to expand the role of libraries within the academic institution. The rewards for libraries include enhanced goal attainment, increased visibility and standing within the institution, strengthened partnerships with administrative and service units, and better funding opportunities. The rewards for institutions of higher education include increased goal attainment, increased competitiveness, and more cost-effective knowledge services. For consumers, knowledge management will mean more knowledge that can be obtained more quickly and that is more closely related to achieving work-related goals.

\section{Similarities and Differences}

In some important ways, knowledge management is merely putting a new name to things that librarians have done for centuries. It is primarily a social, not a technological, technique. The service function and good relations with users, which are the keys to successful librarianship, also are central to knowledge management. The instructional function of libraries is an essential component of knowledge management. The emphasis on meeting user needs as defined by users also is shared..$^{25}$ The selection, organization, and weeding of knowledge are necessary prerequisites to the successful operation of both services. Commitment to staff training is an important part of both knowledge management and library services. Library functions will be at the heart of a knowledge-based organization. And a knowledge-based organization such as an institution of higher education will insist on effective library and knowledge services.

Moreover, there are differences between knowledge management and the practices of most academic libraries. First, knowledge management is almost entirely goal oriented. If the academic goal changes, knowledge management will change rapidly to address the new goal. On the other hand, academic libraries tend to provide services as long as they are used. Second, knowledge management tends to be much more proactive in terms of users. It is more willing to initiate a dialog than libraries have been in the past. Third, libraries traditionally try to be everything to everybody, whereas knowledge management tends to be very focused and selective. Fourth, knowledge management is committed to the time value of knowledge, a concept unknown in academic libraries until recently. Finally, knowledge management is outcomes based, whereas libraries are people based. These differences, though at times profound, need not be overwhelming. As libraries adopt more aspects of the learning organization, and as knowledge management learns more about organizing and supporting knowledge, it is likely that the differences will begin to blur.

\section{Issues}

Knowledge management does present several significant professional issues to librarians. Perhaps the most profound is in the area of proactivity and confidentiality. Librarians tend to resist being proactive, particularly if it means that any information about a user might become public. Circulation records are destroyed routinely. Librarians are reluctant to ask a person how he or she plans to use the information they make available. They decline to determine institutional affiliation before committing significant resources to answering a question. Knowledge management would capture and use all this information. It would use circula- 
tion records to let an individual know whether a book or article in an area he or she uses frequently is available. Knowledge management can use the context of use to refer more scholarly knowledge to the user or to put the user in contact with another person who needs his or her skill or shares his or her interests. It would use institutional affiliation to both protect sensitive information and build alliances. For libraries, knowledge management raises important issues of intellectual freedom that must be addressed.

Academic librarians, like faculty, are not very accountable for their time or resources used. It is assumed that as individual professionals, librarians know best how to manage their time and resources. They may go days or weeks without considering how they are contributing to organizational goals. Given the traditional paucity of library support and the vast quantities they organize, librarians tend to sacrifice speed in their operations. Until recently, they tended to do all their work in like-minded groups. Knowledge management, on the other hand, is based on assumptions of strategic planning, the time value of information, and cross-functional teams. If librarians are to function as key players in knowledge management, some accommodation will have to occur on these functional issues.

Finally, librarians as individuals usually seek the security of a stable organization. They look to the library to guide and support their development as individuals. Knowledge management organizations tend to be more individually based, reflecting the general trend toward organizational autonomy recently described by Peter Drucker. ${ }^{27}$ To be successful collaborators, librarians will need to take a more independent and self-directed approach to their work within knowledge organizations.

\section{Summary}

Knowledge management is a new field drawing on several disciplines, including library and information science. Developed in corporate America, it is beginning to reach public service and educational institutions. Higher education and academic libraries can use knowledge management to achieve organizational goals.

Knowledge management can be incorporated into many library operations to improve effectiveness. In addition, it offers the opportunity to expand the role of libraries in the academic community and to result in strengthened relationships with related units, inside and outside the university.

As a social phenomenon, knowledge management is both similar to and different from academic libraries. Librarians and knowledge management workers must address several issues before they can work together effectively, but the opportunities suggested by their collaboration are great.

\section{Notes}

1. Blaise Cronin, "Information Professionals in the Information Age," International Information and Library Review 30 ( Mar. 1998): 37-50; Michael E. D. Keonig, "Intellectual Capital and Knowledge Management," IFLA Journal 22 (1996): 299-301; Ikujiro Nonaka, "A Dynamic Theory of Organizational Knowledge Creation," Organizational Science 5(Feb. 1994): 14-37; Gifford Pinchot and Elizabeth Pinchot, "The Intelligent Organization," in The Infinite Resource: Creating and Leading the Knowledge Enterprise, ed. William E. Halal (San Francisco: Jossey-Bass, 1998): 191-212.

2. Thomas J. Beckman, "The Current State of Knowledge Management," in Knowledge Management Handbook, ed. Jay Liebowitz (Boca Raton, Fla.: CRC Pr., 1999): 1-22; Rolf Blumentritt and Ron Johnston, "Toward a Strategy for Knowledge Management," Technology Analysis and Strategic Management 11 (Sept. 1999): 287-300; Thomas H. Davenport, David W. De Long, and Michael C. Beers, "Successful Knowledge Management Projects," Sloan Management Review 39 (winter 1998): 43-78; Michael Kull and Kumar S. Nochur, The State of Knowledge Management in the Public Sector (Washington, D.C.: Foundation for Electronic Government, 2000), 18-22.

3. Dorothy Leonard and Susaan Straus, "Putting Your Company's Whole Brain to Work," in Harvard Business Review on Knowledge Management (Cambridge, Mass.: Harvard Business School Pr., 1998): 109-36; William H. Starbuck, "Learning by Knowledge-Intensive Firms," Journal of 
Management Studies 29 (Nov. 1992): 713-40.

4. Foundation for Electronic Government, Knowledge Management Conference Proceedings (Washington, D.C.: Foundation for Electronic Government, 2000).

5. Lucy Marshall, "Facilitating Knowledge Management and Knowledge Sharing : New Opportunities for Information Professionals," Online 21 (Sept./Oct. 1997): 92-98; Paul Vassallo, "The Knowledge Continuum-Organizing for Research and Scholarly Communication," Internet Research: Electronic Applications and Policy 9 (1999): 232-42.

6. Davenport, De Long, and Beers, "Successful Knowledge Management Projects."

7. Richard Y. Wang, Yang W. Lee, Leo L. Pipino, and Diane M. Strong, "Manage Your Information as a Product," Sloan Management Review 39 (summer 1998): 95-105.

8. Laurence Prusak, "Introduction to Knowledge in Organizations," in Knowledge in Organizations, ed. Laurence Prusak (Boston: Butterworth, 1997): ix-xv.

9. Michael J. Earl, "Knowledge as Strategy: Reflections on Skandia International and Shorko Films," in Knowledge in Organizations, ed. Laurence Prusak (Boston: Butterworth, 1997): 1-15.

10. Marjorie A. Lyles and Charles R. Schwenk, "Top Management, Strategy, and Organizational Structures," Journal of Management Studies 29 (Mar. 1992): 155-74.

11. David Krackhardt and Jeffrey R. Hanson, "Informal Networks: The Company," Harvard Business Review 74 (July-Aug. 1993): 104-11.

12. Rob Cross and Lloyd Baird, "Technology Is Not Enough: Improving Performance by Building Organizational Memory," Sloan Management Review 41 (spring 2000): 69-78.

13. Bart Harloe and John M.Budd, "Collection Development and Scholarly Communication in the Era of Electronic Access," Journal of Academic Librarianship 20 (May 1994): 83-87.

14. Marina M. Mann, Richard L. Rudman, Thomas A. Jenckes, and Barbara C. McNurlin, "EPRINET: Leveraging Knowledge in the Electric Utility Industry," in Knowledge in Organizations, ed. Laurance Prusak (Boston: Butterworth, 1997): 73-97.

15. Davenport, De Long, and Beers, "Successful Knowledge Management Projects."

16. New Mexico State University, "Klipsch School of Electrical Engineering in Top 10," 10 Feb. 1999, press release.

17. Vassallo, "The Knowledge Continuum."

18. Steven E. Prokesch, "Unleashing the Power of Learning: An Interview with British Petroleum's John Browne," Harvard Business Review 75 (Sept.-Oct. 1997): 147-68.

19. Blaine Goss, Kenneth Hacker, Valerie Horton, and Charles T. Townley, "Developing Guidelines for Electronic Mail Use in Academic Libraries," Communications Studies and Research 35 (July 1997): 246-65.

20. Nonaka, "A Dynamic Theory of Organizational Knowledge Creation."

21. Richard N. Katz and Associates, ed., Dancing with the Devil: Information Technology and the New Competition in Higher Education (San Francisco: Jossey-Bass, 1999); Filipe Santos, Manuel V. Heitor, and Joao Caraca, "Organizational Challenges for the University," Higher Education Management 10 (Nov. 1998): 87-107.

22. Barbara Ashdown, Kathy Smith, and Deborah York, "Development of a Strategy for Managing Organizational Knowledge," in Knowledge Management Conference Proceedings (Washington, D.C.: Foundation for Electronic Government, 2000): 208-23.

23. University of New Mexico Health Sciences Center, "HSC Advisory Council for Knowledge Management and Information Technology," 31 Mar. 2000, press release.

24. Vassallo, "The Knowledge Continuum."

25. Peter Drucker, “Managing Oneself," Harvard Business Review 77 (Mar.-Apr. 1999): 65-74. 